\title{
Diverse Approaches to Creating and Using Causal Loop Diagrams in Public Health Research: Recommendations From a Scoping Review
}

\author{
Lori Baugh Littlejohns, Carly Hill and Cory Neudorf* \\ Community Health and Epidemiology, University of Saskatchewan, Saskatoon, SK, Canada
}

Objectives: Complex systems thinking methods are increasingly called for and used as analytical lenses in public health research. The use of qualitative system mapping and in particular, causal loop diagrams (CLDs) is described as one promising method or tool. To our knowledge there are no published literature reviews that synthesize public health research regarding how CLDs are created and used.

Methods: We conducted a scoping review to address this gap in the public health literature. Inclusion criteria included: 1) focused on public health research, 2) peer reviewed journal article, 3) described and/or created a CLD, and 4) published in English from January 2018 to March 2021. Twenty-three articles were selected from the search strategy.

Results: CLDs were described as a new tool and were based upon primary and

OPEN ACCESS

Edited by:

Kasia Czabanowska,

Maastricht University, Netherlands

Reviewed by:

Robin van Kessel,

Maastricht University, Netherlands

Brian Li Han Wong,

Independent Researcher, London,

United Kingdom

${ }^{*}$ Correspondence:

Cory Neudorf

cory.neudorf@usask.ca

Received: 16 July 2021 Accepted: 25 November 2021

Published: 14 December 2021

Citation:

Baugh Littlejohns L, Hill C and Neudorf C (2021) Diverse Approaches to Creating and Using Causal Loop Diagrams in Public Health Research:

Recommendations From a

Scoping Review.

Public Health Rev 42:1604352. doi: 10.3389/phrs.2021.1604352 secondary data, researcher driven and group processes, and numerous data analysis methods and frameworks. Intended uses of CLDs ranged from illustrating complexity to informing policy and practice.

Conclusion: From our learnings we propose nine recommendations for building knowledge and skill in creating and using CLDs for future public health research.

Keywords: scoping review, causal loop diagrams, public health research, methods, complex systems thinking

\section{INTRODUCTION}

There is a trend in public health research for the application of complex systems thinking methods and tools [1-3]. We conceptualize public health research from this perspective in terms of examining systems that are complex webs of sectors, institutions, people, structures, and interventions that aspire to maintain and improve population health. Furthermore, we value public health research that is "based on the principles of social justice, attention to human rights and equity, evidence-informed policy and practice, and addressing the underlying determinants of health" [4].

There are published review articles regarding complex systems thinking methods used in public health research and together these paint a broad landscape $[2,3,5-10]$. In this literature, there is clear support for using qualitative system mapping and in particular, causal loop diagrams (CLDs) as analytical tools to embed complex systems thinking. The origins of the use of CLDs emanate from the system dynamics branch of systems science founded by Forrester [11] and CLDs are needed because "we live in a complex of nested feedback loops" [12]. One example of using a CLD in public health research is a study of factors that influenced health promotion policy and practice in a regional public 
health system [13]. Here, the CLD was useful because "feedback mechanisms can be seen as leverage points to strengthen systems" and to "identify potential opportunities to disrupt or slow down vicious feedback mechanisms or amplify those that are virtuous cycles." At the time of this study (2018), there were few examples of CLDs in public health literature [14-21].

To our knowledge there are no published reviews that synthesize public health research in terms of how CLDs are created and used. We were motivated to conduct a literature review to determine how CLD methodology could be used to identify leverage points in local public health systems to strengthen the response to COVID-19 in Canada. The aim of this paper is to address this gap in the literature and synthesize knowledge from recent innovations for our research and contribute to knowledge development. We posed two research questions: 1) How are CLDs created and used in recent (>2018) public health research? 2) What recommendations emerge regarding how to create and use CLDs in public health research?

\section{METHODS}

A scoping review was chosen for this study in order "to examine how research is conducted" and "to provide an overview or map of the evidence" [22]. A narrative synthesis approach was utilized as the topic required exploration more than explanation and human and time resources were limited [23]. Key issues identified by Byrne [24] to strengthen the review were addressed such as ensuring transparency in search strategy and data extraction, analysis and synthesis.

\section{Search Strategy}

Literature was searched using the Scopus and PubMed databases and used the following search terms: causal loop diagram ${ }^{\star}$, complex $^{\star}$, system ${ }^{\star}$ thinking, method ${ }^{*}$, tool, approach, research, and public health. Inclusion criteria were 1) public health research, 2) peer reviewed journal article, 3) described or created a CLD as a research method, and 4) published in English from January 2018 to March 2021. The key objective was to find state-of-the-field examples of CLDs, therefore, extensive hand searches of references was completed. It is important to note that piloting this search strategy uncovered numerous articles that only mentioned CLDs and did not explicitly meet the criteria of "described or created a CLD as a research method." While we set out to use PRISMA guidelines we deemed it unnecessary given the search strategy quickly became one of including all articles that meet our inclusion criteria.

\section{Data Extraction and Analysis}

Study selection was conducted by one author (LBL) while appraisal and duplicate independent data extraction and validation was conducted by two authors ( $\mathrm{LBL}$ and $\mathrm{CH}$ ). $\mathrm{CN}$ provided input throughout the study and facilitated discussion about any differences. Data extraction followed these six categories:

1) Research aim,

2) Description of complex systems thinking,
3) Why a CLD was selected as a method,

4) How the CLD was created,

5) How the CLD was used, and

6) Recommendations for future research using CLDs.

Two authors (LBL and $\mathrm{CH}$ ) extracted verbatim text that aligned with the extraction categories and these were saved to a spreadsheet. Both authors reviewed the spreadsheet in its entirety, discussed individual articles to gain clarity, and wrote summary paragraphs to identify high level themes. Following this, for each article, summary statements were written for the six extraction categories and a table was created. The two authors reviewed each other's summaries for accuracy and revisions were made. Finally, directed content analysis was used to interpret extracted data "through systematic classification of coding and identifying themes and patterns" [25].

\section{RESULTS}

We found 23 articles in total that met our inclusion criteria. A list of these articles and summary statements are provided in Table 1. This section answers our first research question: How are CLDs created and used in recent (>2018) public health research? The organization of this section mirrors the six data extraction categories indicated above.

\section{Research Aims}

Although the literature addressed a range of public health topics, non-communicable disease prevention was most frequently addressed (15/23) and of those, seven were focused on obesity prevention. Table 2 provides a list of research topics.

In terms of research aims found in the 23 articles, four themes emerged: 1) to examine the complexity of a public health topic and illustrate complex systems thinking [26-34];2) to discuss the complexity of a public health intervention [35-40]; 3) to describe study protocol and how CLDs were created [41-44]; and 4) to illustrate how CLDs can be used to monitor and track initiatives to improve population health or evaluate impact of interventions [45-48].

\section{Complex Systems Thinking}

Complex systems thinking was discussed in terms of systems, problems, interventions, and key concepts that drive this type of approach. Several articles indicated that the systems they were studying were complex, for example:

A complex system may be characterized by its heterogeneity (various actors and structures at different levels); its dynamic, interactive, and adaptive nature (its ability to respond to or resist external changes, or changes in the interacting parts); and its emergent properties (arising through interactions between processes or factors that alone do not exhibit such properties) [30]. 
TABLE 1 | Summary statements of extracted data (Canada, 2021).

\begin{tabular}{|c|c|c|c|c|c|}
\hline $\begin{array}{l}\text { First } \\
\text { author/citation }\end{array}$ & Research aim & $\begin{array}{l}\text { Description: complex } \\
\text { systems thinking }\end{array}$ & $\begin{array}{l}\text { Why a } \\
\text { CLD was } \\
\text { selected as } \\
\text { a method }\end{array}$ & $\begin{array}{l}\text { How the } \\
\text { CLD was } \\
\text { created }\end{array}$ & $\begin{array}{l}\text { How the } \\
\text { CLD was } \\
\text { used }\end{array}$ \\
\hline Allender [47] & $\begin{array}{l}\text { To report on insight } \\
\text { gathered during } \\
\text { development, } \\
\text { implementation, and } \\
\text { evaluation of the first } \\
2 \text { years in a systems-based } \\
\text { childhood obesity } \\
\text { prevention initiative that } \\
\text { was inspired by community } \\
\text { based system dynamics }\end{array}$ & $\begin{array}{l}\text { Complexity hampers } \\
\text { traditional approaches to } \\
\text { improving population } \\
\text { health; need to } \\
\text { conceptualize health as the } \\
\text { result of actors and } \\
\text { "interdependent elements } \\
\text { connected at multiple } \\
\text { levels"; initiatives such as } \\
\text { obesity prevention need to } \\
\text { address feedback loops } \\
\text { that can lead to policy } \\
\text { resistance, time delays that } \\
\text { influence long term system } \\
\text { change, and accumulations } \\
\text { and their rates of change }\end{array}$ & $\begin{array}{l}\text { To create a visual model of } \\
\text { the causes and effects of } \\
\text { childhood obesity }\end{array}$ & $\begin{array}{l}\text { Local behavioral data } \\
\text { (collected using a } \\
\text { monitoring system and } \\
\text { electronic tablets) was } \\
\text { used to support the } \\
\text { creation of CLD during } \\
\text { group model building in } \\
\text { communities }\end{array}$ & $\begin{array}{l}\text { Create engagement ("whole } \\
\text { community") and momentum } \\
\text { for the intervention } \\
\text { communities to take action } \\
\text { on childhood obesity }\end{array}$ \\
\hline Araz [45] & $\begin{array}{l}\text { To analyze potential "real } \\
\text { world" impacts of policy } \\
\text { interventions on improving } \\
\text { roadway safety regarding } \\
\text { drugged driving behavior, } \\
\text { road environment, and } \\
\text { policy through system } \\
\text { dynamics modeling }\end{array}$ & $\begin{array}{l}\text { Driver behavior was } \\
\text { described as a complex } \\
\text { system given the dynamic } \\
\text { interrelationships and } \\
\text { multidimensional variables } \\
\text { associated with driving } \\
\text { behaviors, policy, } \\
\text { environment, and roadway } \\
\text { conditions }\end{array}$ & $\begin{array}{l}\text { To illustrate variables that } \\
\text { influence drugged driving } \\
\text { behaviors, road } \\
\text { environment and traffic } \\
\text { safety policies }\end{array}$ & $\begin{array}{l}\text { Researchers reviewed the } \\
\text { literature and published } \\
\text { data is determine } \\
\text { parameters and a stock- } \\
\text { flow diagram was used to } \\
\text { create the CLD and } \\
\text { quantitative expressions } \\
\text { were derived for } \\
\text { simulation modeling }\end{array}$ & $\begin{array}{l}\text { A component of system } \\
\text { dynamics modeling to } \\
\text { provide insight into the } \\
\text { dynamic complexity of the } \\
\text { drugged driving environment } \\
\text { and traffic safety policy }\end{array}$ \\
\hline Bensberg [35] & $\begin{array}{l}\text { To describe the } \\
\text { establishment of a multi- } \\
\text { community chronic disease } \\
\text { prevention initiative (Healthy } \\
\text { Together Victoria) through a } \\
\text { systems thinking lens }\end{array}$ & $\begin{array}{l}\text { A way to address complex } \\
\text { public health problems; } \\
\text { holistic vs. reductionist } \\
\text { perspective; the essence of } \\
\text { a system is the causal } \\
\text { connections between parts } \\
\text { and feedback loops }\end{array}$ & $\begin{array}{l}\text { To summarize findings and } \\
\text { illustrate feedback loops }\end{array}$ & $\begin{array}{l}\text { CLD was created by } \\
\text { researchers from the } \\
\text { analysis interview data }\end{array}$ & $\begin{array}{l}\text { Identify strengths, limitations, } \\
\text { and "possible remedies for } \\
\text { the purpose of advancing } \\
\text { health infrastructure } \\
\text { initiatives and reforms." }\end{array}$ \\
\hline Bradley [34] & $\begin{array}{l}\text { To report on the } \\
\text { importance of employing } \\
\text { systems thinking for the } \\
\text { prevention and response to } \\
\text { COVID-19 }\end{array}$ & $\begin{array}{l}\text { Society is a complex } \\
\text { adaptive system with } \\
\text { interconnected factors } \\
\text { impacting the spread of } \\
\text { infection; system structure } \\
\text { influences system } \\
\text { behaviour; systems change } \\
\text { is needed to mitigate } \\
\text { COVID-19 }\end{array}$ & $\begin{array}{l}\text { To visualize the causal } \\
\text { connections and } \\
\text { components of society to } \\
\text { better understand feedback } \\
\text { loops and relationships } \\
\text { impacting the entire status } \\
\text { of a system impacted by } \\
\text { COVID-19 }\end{array}$ & $\begin{array}{l}\text { CLD was created by } \\
\text { researchers only }\end{array}$ & $\begin{array}{l}\text { Provide a visual example of } \\
\text { the dynamic and complex } \\
\text { interactions and systems } \\
\text { changes needed to address } \\
\text { COVID-19 }\end{array}$ \\
\hline Brereton [28] & $\begin{array}{l}\text { To explore the complex } \\
\text { causal relationships } \\
\text { between children's health, } \\
\text { environment, social, and } \\
\text { economic influences in } \\
\text { least developed countries }\end{array}$ & $\begin{array}{l}\text { A science that explores } \\
\text { how parts connect, react, } \\
\text { and interact to increase } \\
\text { recognition of non-linearity } \\
\text { and cause and effect } \\
\text { relationships; to view the } \\
\text { "forest and the trees." }\end{array}$ & $\begin{array}{l}\text { A tool to uncover root } \\
\text { problems that are often } \\
\text { difficult to view within } \\
\text { complex systems; "Each } \\
\text { CLD tells a story that links } \\
\text { cause and effect through } \\
\text { feedback" and that can be } \\
\text { used to surface mental } \\
\text { models and policy decisions } \\
\text { among stakeholders }\end{array}$ & $\begin{array}{l}\text { CLD was created from } \\
\text { data on the most } \\
\text { significant causes of } \\
\text { childhood mortality and a } \\
\text { narrative literature review }\end{array}$ & $\begin{array}{l}\text { Highlight potential leverage } \\
\text { points in children's health } \\
\text { and enable greater insight for } \\
\text { policy and practice }\end{array}$ \\
\hline Brown [48] & $\begin{array}{l}\text { To present how a } \\
\text { community used a CLD to } \\
\text { track the underlying system } \\
\text { changes resulting from } \\
\text { implementing a healthy }\end{array}$ & $\begin{array}{l}\text { A method to address } \\
\text { complexity }\end{array}$ & $\begin{array}{l}\text { To present the relationships } \\
\text { and variables that influence } \\
\text { complex problems }\end{array}$ & $\begin{array}{l}\text { CLD was created from } \\
\text { seven group model } \\
\text { building sessions where } \\
\text { implementation strategies } \\
\text { were tracked }\end{array}$ & $\begin{array}{l}\text { Demonstrate how a CLD can } \\
\text { be used to measure system } \\
\text { changes and evaluate } \\
\text { obesity prevention } \\
\text { interventions }\end{array}$ \\
\hline
\end{tabular}

eating curriculum in a

school 
TABLE 1 | (Continued) Summary statements of extracted data (Canada, 2021).

\begin{tabular}{|c|c|c|}
\hline $\begin{array}{l}\text { First } \\
\text { author/citation }\end{array}$ & Research aim & $\begin{array}{l}\text { Description: complex } \\
\text { systems thinking }\end{array}$ \\
\hline
\end{tabular}

\section{Why a \\ CLD was \\ selected as}

a method
How the

CLD was

created

\section{How the \\ CLD was \\ used}

Burrell [36]

To develop a concept model of key causal structures driving dynamics of community violence escalation over time in a context of historical racism to study complex problems To represent "dynamic as the manifestation of dynamic interactions among their constituent parts hypotheses" about the system structure producing observed outcomes over time; illustrate complex interactions (e.g., interdependence, delays between cause and effect, mutual interaction, and feedback loops reinforcing or counteracting earlier changes)

Clarke [37] To examine the dynamics and decisions regarding obesity prevention policy adoption within multicommunity chronic disease prevention initiative (Healthy Together Victoria)

A non-linear and holistic perspective; appreciation of the multiple, interacting forces guiding policy decisions; understanding system behavior in terms of structures and patterns and feedback mechanisms

Crielaard [26] To model social norms
regarding body weight and obesity prevalence using system dynamics modeling
A complex system is nonlinear, is more than the aggregation of its parts, and has feedback loops that influence emergent system behaviour
A heuristic tool to help document interconnections, virtuous/vicious feedback mechanisms, and leverage points to inform strategies for systems change

To conceptualize the system and inform system dynamic modeling; a means to simulate "what if" scenarios and emergent system behavior to better understand the causal links and variables at play
A tool in system dynamic modeling
Eker [27] To combine quantitative simulation modelling, an interpretivist approach, and a participatory method to examine housing, energy and wellbeing aspects of the UK's housing stock

To understand the dynamic behavior of complex systems or the systems underlying a policy problem and causal feedback thinking and non-linearity among elements; to examine the complexity of interactions between housing, energy and wellbeing

\section{Gerritsen [41]}

\begin{tabular}{|c|c|}
\hline Gerritsen [41] & $\begin{array}{l}\text { To describe group model } \\
\text { building and system } \\
\text { mapping methods used to } \\
\text { study fruit and vegetable } \\
\text { intake among children and } \\
\text { evaluate effectiveness of } \\
\text { various tools (graphs over } \\
\text { time, cognitive mapping } \\
\text { and CLDs) }\end{array}$ \\
\hline $\begin{array}{l}\text { Hassmiller } \\
\text { Lich [46] }\end{array}$ & $\begin{array}{l}\text { To report on group concept } \\
\text { mapping and system } \\
\text { dynamics modeling as } \\
\text { complimentary methods to } \\
\text { address complex problems } \\
\text { in evaluation and strategic } \\
\text { planning }\end{array}$ \\
\hline
\end{tabular}

A way to address complex problems characterized as having multiple causes, multilevel contexts, no single solution, and action requiring multisectoral

\section{A way to increase} understanding of interconnected factors and cause and effect relationships that influence public health, social, behavioral, or environmental problems
To increase understanding of the effectiveness of
CLD was created by researchers using data from interviews, documents, and fields notes
CLDs were created from stakeholder interviews,

documentaries, an ethnography, and a literature review
Convey new theoretical insights and implications regarding the interplay of factors for reducing violence escalation and disparity
Enhance theoretical analysis of obesity prevention policy and demonstrate feedback loops and leverage points that either spurred or resisted obesity prevention policy

\section{CLD was created after} conducting interviews with experts and the causal links found during the interviews were confirmed via literature review

CLD created as part of participatory system dynamics (SD) modelling that included stakeholder interviews and group model building
Inform simulation scenarios and policy decision-making for group-level obesity interventions
To increase understanding of the dynamics of complex problems and system behavior, the feedback mechanisms at play, and the determinants of fruit and vegetable intake among children
CLD created from data obtained through group model building

For simulation modelling and results were to inform policy debates

To engage stakeholders in identifying and visualizing cause-effect relationships among variables
CLD created from data collected through group concept mapping
Identify system change actions and increase understanding about complex systems and systems thinking

\begin{tabular}{ll}
\hline Jalali [38] & $\begin{array}{l}\text { To increase understanding } \\
\text { of the effectiveness of }\end{array}$
\end{tabular}
A step in system dynamic
modeling
Identify leverage points for strategic planning and intervention scenarios 
TABLE 1 | (Continued) Summary statements of extracted data (Canada, 2021).

$\begin{array}{llc}\text { First } & \text { Research aim } & \begin{array}{c}\text { Description: complex } \\ \text { systems thinking }\end{array}\end{array}$

\section{systems thinking}

\section{Why a \\ CLD was \\ selected as}

a method
How the

CLD was

created

CLD created from

interview data and

published data

\section{How the \\ CLD was \\ used}

obesity prevention interventions from an organizational behavior or dynamics perspective and use system dynamic

Klement [29] To include individual level factors that influence COVID-19 to Sahin et al's (2020) CLD of environmental-healthsocio-economic systems of the COVID-19 pandemic

\begin{tabular}{ll}
\hline Knai [30] & To demonstrate the \\
& application of a complex \\
& systems approach to \\
& analyze the commercial \\
& determinants of health in \\
& terms of problem \\
& identification and policy \\
& development
\end{tabular}
endogenous, modeling methods
To study the complexity or dynamics of program success and failure implementation of interventions in order to avoid the dynamics that lead to poor outcomes

To increase understanding the interconnections A step in system dynamic modeling among parts of a system, feedback loops, system structure and behavior at multiple levels

Attends to heterogenous

Maitland [42] To report on study protocol To examine complexity,
for applying a 'whole of system approach' to evaluate strategies to address childhood obesity

\begin{tabular}{ll}
\hline Osman [31] & To report on applying \\
& systems thinking methods \\
& and tools to identify \\
& interdependence and \\
& underlying factors that \\
& influence TB. \\
\hline Owen [39] & To report on applying \\
& systems thinking and \\
& feedback loops to create a \\
& CLD to visualize and \\
& understand the dynamic \\
& complexity of a successful \\
intervention to address \\
childhood obesity \\
To study roles of \\
community health \\
volunteers in managing \\
diabetes and hypertension \\
among Syrian refugees and \\
recommend improvements \\
To report on a novel \\
combination of systems \\
methods and tools and \\
systemic inquiry processes \\
in a study of community- \\
based chronic disease \\
prevention
\end{tabular}

To illustrate the complexity effectiveness of public
CLD created from researcher knowledge, evidence, and assumptions
Illustrate the complexity of COVID-19
CLD created from researcher knowledge, evidence and assumptions stakeholders and interventions, their dynamic interactions at multiple levels, adaptation and emergent system behavior, nonlinearity, feedback loops, and power dynamics in systems in order to influence systems to be more health promoting nonlinearity, among variables, and feedback loops of COVID-19 and the health measures

Identify interventions and further research that highlights the interdependence among variables such as market and nonmarket strategies and sectors and how they work together to form system behavior with respect to commercial determinants of noncommunicable diseases

To visualize the system by illustrating system components and interconnections that results in a narrative about a problem

Health systems are One component of a larger

complex adaptive systems; study to focus on many interactions among parts produces system behaviour

To understand system structure, feedback loops, non-linearity, delays, system behavior, factors that influence complex problems, and to identify interventions

To examine complex adaptive systems in terms of non-linear interactions among multiple actors and processes

An analytic or conceptual lens (to study three organizing principles: interdependent relationships, perspectives and boundaries); systemic inquiry as a process to build nonlinearity of relationships among factors, feedback loops, and changes in context

To identify and share understanding of system elements and nonlinear system structures that influences or dictates system behaviour

To understand complex systems and impact and/or consequences of changes to programming
Study protocol; Did not create a CLD
Study protocol; Did not create or use a CLD.

\section{To support community} members and researchers to examine influencing factors of local systemic problems with respect to chronic disease prevention

\section{CLD created from a} seminar with diverse experts; utilized fishbone analysis, a 5 whys approach, and affinity diagrams

CLD created from
interview data
To develop implementation action plans, risk mitigation strategies and track changes in the system

To evaluate project implementation in order to understand leverage points to strengthen systems and/ or create new systems

\section{CLD created from \\ To identify issues and document review, key informant interviews, and workshops strategies for improving the community health workers program}

\section{CLD created from group To highlight feedback loops modeling building in each that are either reinforcing or participating community balancing and identify places} to intervene 
TABLE 1 | (Continued) Summary statements of extracted data (Canada, 2021).

\begin{tabular}{|c|c|c|c|c|c|}
\hline $\begin{array}{l}\text { First } \\
\text { author/citation }\end{array}$ & Research aim & $\begin{array}{l}\text { Description: complex } \\
\text { systems thinking }\end{array}$ & $\begin{array}{l}\text { Why a } \\
\text { CLD was } \\
\text { selected as } \\
\text { a method }\end{array}$ & $\begin{array}{l}\text { How the } \\
\text { CLD was } \\
\text { created }\end{array}$ & $\begin{array}{l}\text { How the } \\
\text { CLD was } \\
\text { used }\end{array}$ \\
\hline Sahin [32] & $\begin{array}{l}\text { To visualize the complexity } \\
\text { in managing the COVID-19 } \\
\text { pandemic through a } \\
\text { systems lens by identifying } \\
\text { the interconnectivity } \\
\text { between health, economic, } \\
\text { social and environmental } \\
\text { aspects }\end{array}$ & $\begin{array}{l}\text { capacity for ongoing action } \\
\text { learning } \\
\text { A framework to better } \\
\text { understand the big picture } \\
\text { through identifying the } \\
\text { multi-faceted } \\
\text { consequences of decisions } \\
\text { and to design the most } \\
\text { effective strategies to } \\
\text { manage the impacts of } \\
\text { unintended consequences }\end{array}$ & $\begin{array}{l}\text { To identify and illustrate } \\
\text { feedback relationships and } \\
\text { pinpointed leverage points }\end{array}$ & $\begin{array}{l}\text { CLD created from } \\
\text { researchers existing } \\
\text { knowledge, geographical } \\
\text { data, and government } \\
\text { documents via four expert } \\
\text { workshops }\end{array}$ & $\begin{array}{l}\text { To identify leverage points to } \\
\text { address COVID-19 }\end{array}$ \\
\hline Swierad [44] & $\begin{array}{l}\text { To describe how group } \\
\text { model building was } \\
\text { conducted and report on } \\
\text { the findings with respect to } \\
\text { childhood obesity }\end{array}$ & $\begin{array}{l}\text { Obesity is discussed in } \\
\text { terms of a complex, multi- } \\
\text { level problem }\end{array}$ & $\begin{array}{l}\text { To support community } \\
\text { members to understand } \\
\text { concepts and tools of } \\
\text { system dynamics and } \\
\text { systems thinking }\end{array}$ & $\begin{array}{l}\text { CLD created from group } \\
\text { model building }\end{array}$ & $\begin{array}{l}\text { To illustrate and increase } \\
\text { understanding of childhood } \\
\text { obesity as a multifactorial } \\
\text { problem (e.g., sociocultural } \\
\text { factors), tailor culturally } \\
\text { sensitive interventions, and } \\
\text { generate hypotheses for } \\
\text { further research }\end{array}$ \\
\hline $\begin{array}{l}\text { Urwannachotima } \\
\text { [33] }\end{array}$ & $\begin{array}{l}\text { To study the dynamic } \\
\text { interactions among } \\
\text { variables associated with } \\
\text { sugar-sweetened beverage } \\
\text { tax and dental caries in } \\
\text { Thailand }\end{array}$ & $\begin{array}{l}\text { To take a whole system } \\
\text { perspective of dynamic } \\
\text { interactions }\end{array}$ & $\begin{array}{l}\text { To visualize dynamic } \\
\text { interactions or relationships } \\
\text { among variables and their } \\
\text { interdependence }\end{array}$ & $\begin{array}{l}\text { CLD created from in- } \\
\text { depth interviews and } \\
\text { group model building }\end{array}$ & $\begin{array}{l}\text { The potential of the CLD lies } \\
\text { with quantitative modeling } \\
\text { and formulating } \\
\text { recommendations for } \\
\text { intervention }\end{array}$ \\
\hline
\end{tabular}

TABLE 2 | Research topics of reviewed literature (Canada, 2021).

\begin{tabular}{lc} 
Research topic & Citation \\
\hline Children's Health & {$[28]$} \\
Community Violence & {$[36]$} \\
COVID-19 & {$[29,32,34]$} \\
Driving Behavior & {$[45]$} \\
Evaluation & {$[46]$} \\
Housing & {$[27]$} \\
Noncommunicable disease prevention & \\
Commercial Determinants of Health & {$[30]$} \\
Diabetes/Hypertension/Community Health Workers & {$[40]$} \\
Healthy Schools & {$[48]$} \\
Prevention Systems & {$[35,43]$} \\
Sugar Sweetened Beverage Tax & {$[33]$} \\
Obesity Prevention: Organizational dynamics & {$[38]$} \\
Obesity Prevention: Weight-Related Behavior & {$[26]$} \\
Obesity Prevention: Children & {$[39,44,47]$} \\
Obesity Prevention: Fruit and Vegetable Intake & {$[41]$} \\
Obesity Prevention: Policy & {$[37]$} \\
Obesity Prevention: Whole of system & {$[42]$} \\
Tuberculosis & {$[31]$}
\end{tabular}

Following on this, feedback loops in complex systems were explicitly discussed in all articles to some extent. Jalali et al. [38] described these in terms of "causal chains of multiple variables in which changes in each variable could be traced back to its historical values." They go on to define the difference between reinforcing and balancing feedback loops.

Another way complex systems thinking was described was with respect to complex problems and interventions. Burrell et al. [36] discussed community violence in terms of embedded contexts and the lack of holistic understanding of such "dynamic complexity." Complex problems and interventions were often discussed together. The need to move away from "isolated intervention thinking" to systemic interventions to study systems change was highlighted by Knai et al. [30].

All articles built upon the descriptions reported above in some manner when discussing complex systems thinking. Some articles described this as providing "the opportunity to understand, test, and revise our understanding of how the different components in a system work together" [31] and "to study complex problems as the manifestation of dynamic interactions among their constituent parts" [36]. Furthermore, a few articles expanded the discussion to include such concepts as boundary judgement $[38,43,47]$, that is, "establishing boundaries to the system is a fundamental starting point to efforts to change systems" [47].

\section{Why Causal Loop Diagrams?}

CLDs were mostly seen as a means or a tool to examine feedback at play in public health issues. Some articles were explicit [28, 32, $33,40,43,44]$ while others implied this. Both Riley et al. [43] and Parmar et al. [40] labeled this as "causal loop analysis" and the resulting CLDs were a means to understand systems and potential 
TABLE 3 | How causal loop diagrams were created (Canada, 2021).

\begin{tabular}{|c|c|c|c|c|c|c|}
\hline \multirow{2}{*}{$\begin{array}{l}\text { First } \\
\text { Author/Citation }\end{array}$} & \multicolumn{3}{|c|}{ Data used for CLD creation } & \multicolumn{3}{|c|}{ Process used for CLD creation } \\
\hline & Primary data & Secondary data & Researcher knowledge & $\begin{array}{c}\text { Researcher created } \\
\text { only }\end{array}$ & $\begin{array}{l}\text { Researcher created } \\
\text { with stakeholder } \\
\text { refinement }\end{array}$ & $\begin{array}{c}\text { GMB with } \\
\text { Stakeholders }\end{array}$ \\
\hline Allender [47] & $\checkmark$ & & & & & $\checkmark$ \\
\hline Araz [45] & & $\checkmark$ & & $\checkmark$ & & \\
\hline Bensberg [35] & $\checkmark$ & & & $\checkmark$ & & \\
\hline Bradley [34] & & & $\checkmark$ & $\checkmark$ & & \\
\hline Brereton [28] & & $\checkmark$ & & $\checkmark$ & & \\
\hline Brown [48] & $\checkmark$ & & & & & $\checkmark$ \\
\hline Burrell [36] & $\checkmark$ & $\checkmark$ & & $\checkmark$ & & \\
\hline Clarke [37] & $\checkmark$ & $\checkmark$ & & $\checkmark$ & & \\
\hline Crielaard [26] & $\checkmark$ & $\checkmark$ & & $\checkmark$ & & \\
\hline Eker [27] & $\checkmark$ & & & & & $\checkmark$ \\
\hline Gerritsen [41] & $\checkmark$ & & & & & $\checkmark$ \\
\hline Hassmiller Lich [46] & $\checkmark$ & & & & & $\checkmark$ \\
\hline Jalali [38] & $\checkmark$ & $\checkmark$ & & $\checkmark$ & & \\
\hline Klement [29] & & $\checkmark$ & & $\checkmark$ & & \\
\hline Knai [30] & & $\checkmark$ & & $\checkmark$ & & \\
\hline Maitland [42] & $\checkmark$ & & & & & $\checkmark$ \\
\hline Osman [31] & $\checkmark$ & & & & & $\checkmark$ \\
\hline Owen [39] & $\checkmark$ & & & & $\checkmark$ & \\
\hline Parmar [40] & $\checkmark$ & $\checkmark$ & & & $\checkmark$ & \\
\hline Riley [43] & $\checkmark$ & & & & & $\checkmark$ \\
\hline Sahin [32] & $\checkmark$ & $\checkmark$ & & & & $\checkmark$ \\
\hline Swierad [44] & $\checkmark$ & & & & & $\checkmark$ \\
\hline Urwannachotima [33] & $\checkmark$ & & & & & $\checkmark$ \\
\hline
\end{tabular}

“programming." Using a CLDs was a new tool for some [42, 46] and as one article related, "business as usual" was not working to address obesity [47]. CLDs were also considered a tool to help tell a story. For example, a CLD was thought to support the development of "a concise narrative about a particular problem" [42] and Brereton et al. [28] stated that "every causal loop tells a story that links cause and effect through feedback."

\section{How Were Causal Loop Diagrams Created?}

There were many combinations of methods used to create CLDs. In this section we present this diversity in terms of 1) data sources, 2) processes, 3) data analysis, 4) frameworks, and 5) diagramming (Table 3).

\section{Data Sources}

Both primary and secondary data were used for creating CLDs (Table 3). Most articles reported on primary data collection (18/ 23) and this included interviews [26, 27, 33, 35-40], group model building with stakeholders and/or community members [32, 41, 43, 44, 46, 48], behavioral data [42, 47], fieldnotes [37], and workshops with experts [31]. Twelve articles used primary data only.

Secondary data was used in 10 articles [26, 28-30, 32, 36-38, $40,45]$ and this consisted of document and/or literature review (Table 3). Of the eighteen articles that reported on primary data collection, six included document review [26, 32, 36-38, 40]. Documents included policy briefings, reports, consultation papers, and evaluation reports [37], documentaries and ethnographies [36], program data [38], geographical information and government documents [32], and data from published databases [28, 37, 45]. Literature reviews were undertaken in four articles and these either supplemented primary data [26], secondary data [28, 45], or both [36]. Document and literature review were utilized in four articles [28-30, 45].

\section{Processes}

There were three processes used to create CLDs: group model building, researcher created only, and researcher created with stakeholder refinement (Table 3). Group model building (GMB) was the most common process as reported in 11 articles [27, 31-33, 41-44, 46-48]. Urwannachotima et al. [33] described GMB as "an established methodology for engaging stakeholders to gain mutual understanding of complex relationships and to collectively develop comprehensive systems models that represent the cause and effect relationships of a problem." They go further to explain that "stakeholders are deeply and actively involved in the process of model construction through the exchange, assimilation, and integration of mental models into a holistic system description." GMB was generally reported to be a process where participants brainstormed and named potential variables, drew connections and feedback loops between the identified variables, and then mapped these ideas onto a final CLD. However, there was a variety of GMB processes used and was often not clearly described in terms of session design and activities. Beyond GMB, Hassmiller Lich et al. [46] discussed group concept mapping and Gerritsen et al. [41] described graphing over time and cognitive mapping. 
TABLE 4 | How causal loop diagrams were intended to be used (Canada, 2021).

First

author/citation

\begin{tabular}{|c|c|c|c|c|c|c|c|c|}
\hline \multicolumn{9}{|c|}{ How were CLDS primarily intended to be used } \\
\hline $\begin{array}{l}\text { Inform } \\
\text { policy }\end{array}$ & $\begin{array}{l}\text { Identify } \\
\text { leverage } \\
\text { points } \\
\text { systems } \\
\text { change }\end{array}$ & $\begin{array}{l}\text { Inform } \\
\text { practice }\end{array}$ & $\begin{array}{c}\text { For system } \\
\text { dynamic } \\
\text { modelling }\end{array}$ & $\begin{array}{c}\text { Measure } \\
\text { or } \\
\text { evaluate }\end{array}$ & $\begin{array}{c}\text { Stakeholder } \\
\text { engagement } \\
\text { to take } \\
\text { action }\end{array}$ & $\begin{array}{l}\text { To illustrate } \\
\text { complexity }\end{array}$ & $\begin{array}{l}\text { To inform } \\
\text { future } \\
\text { research }\end{array}$ & $\begin{array}{c}\text { To } \\
\text { enhance } \\
\text { theory }\end{array}$ \\
\hline
\end{tabular}

\section{Allender [47]}

Araz [45]

Bensberg [35]

Bradley [34]

Brereton [28]

Brown [48]

Burrell [36]

Clarke [37]

Crielaard [26]

Eker [27]

Gerritsen [41]

Hassmiller Lich [46]

Jalali [38]

Klement [29]

Knai [30]

Maitland [42]

Osman [31]

Owen [39]

Parmar [40]

Riley [43]

Sahin [32]

Swierad [44]

Urwannachotima

[33]

Allender [47]

Araz [45]

Bensberg [35]

Bradley [34]

Brereton [28]

Brown [48]

Burrell [36]

Clarke [37]

Crielaard [26]

Eker [27]

Gerritsen [41]

Hassmiller Lich [46]

Jalali [38]

Klement [29]

Knai [30]

Maitland [42]

Osman [31]

Owen [39]

Parmar [40]

Riley [43]

Sahin [32]

Swierad [44]

Urwannachotima

[33]

$\begin{array}{lll}\checkmark & \checkmark \\ \checkmark & \checkmark \\ \checkmark & \checkmark & \\ \checkmark & \checkmark & \checkmark\end{array}$

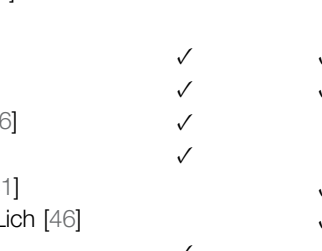

$$
\begin{array}{ll}
\checkmark & \checkmark \\
\checkmark & \checkmark \\
& \checkmark \\
\checkmark & \\
\checkmark &
\end{array}
$$

\begin{tabular}{|c|c|}
\hline & 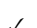 \\
\hline
\end{tabular}

2
$\checkmark$
$\checkmark$
$\checkmark$
$\checkmark$

$\begin{array}{ll}\checkmark & \checkmark \\ \checkmark & \checkmark \\ \checkmark & \checkmark \\ \checkmark & \checkmark \\ \checkmark & \checkmark \\ & \checkmark\end{array}$

$\checkmark$
$\checkmark$
$\checkmark$
$\checkmark$
$\checkmark$
$\checkmark$

$\checkmark$




\section{Data Analysis}

Overall, we found that description was often lacking regarding qualitative data analysis methods used. However, some articles $[35,37,39]$ that collected primary data discussed methods described by Kim and Anderson [49]. Others such as Owen et al. [39] created a table to demonstrate how they used coded interview transcript statements to inform their CLD. Steps in the analysis included 1) using coded text to show causal linkages, 2) translating these to cause-and-effect variables, and 3) creating word-and-arrow diagrams for CLD use. Similarly, Brereton and Jagals [28] presented a table to identify variables and describe influencing links.

\section{Frameworks}

Several articles applied specific frameworks to inform research. For example, Allender et al. [47] used FosterFishman's [50] theoretical framework of six elements (i.e., systems norms, financial resources, human resources, social resources, regulations, and operations) to study root causes, system interactions, and levers for change. Similarly, Baugh Littlejohns and Wilson's [5] framework of seven attributes of effective prevention systems (i.e., leadership, resources, health equity paradigm, information, implementation of desired actions, complex systems thinking, collaborative capacity) was used by Bensberg et al. [35] in their study design.

\section{Diagramming}

Many articles reported on the use of software for creating the actual diagram. Vensim [31, 35, 37, 39, 40, 44-46], Stella Architect [28], and STICK-E [43] were the three diagrammatic programs used. Further to the actual diagram, there was a wide array of CLD types and degrees of diagram readability. We found that some CLDs were kept quite simple, with fewer variables, arrows, and loops, while others were very complicated. For example, Brereton et al. [28] created a tightly packed and dense color-coded main CLD and six diagrams of various feedback loops to highlight key variables, relationships, and potential leverage points. Overall, we found that key variables in blocks or shapes, labelled arrows and feedback loops, color coding, legends, and clear diagram interpretation descriptions were important aspects for readability.

\section{Intended Uses of Causal Loop Diagrams}

There were nine ways that CLDs were intended to be used and these are identified in Table 4. The following provides examples of each intended use.

\section{Illustrate Complexity and Identify Leverage Points}

Illustrating complexity was aligned with research aims in several articles (Table 4) and was implicit in the other articles with respect to using CLDs. Identifying leverage points was explicitly discussed in twelve articles. Osman et al. [31] found that key variables and their interactions pointed to strategies to enhance leadership "through a reduction in bureaucracy in the health system." Similarly, Bensberg et al. [35] identified leadership as a leverage point as well as knowledge and data, resources, workforce, and collaborative relationships that need to be "nudged in the desired direction." One of the more detailed descriptions of leverage points was from Sahin et al. [32]. They adapted Meadows [51] framework of places to intervene in system to identify shallow or deep leverage points to address the "wicked complexity" of the COVID-19 pandemic.

\section{Inform Policy and Practice}

Informing policy was a reported intended use of CLDs in twelve articles (Table 4). Some articles were detailed in offering policy directions while others simply stated that the CLD could inform policy. Clarke et al. [37] examined "key influences on policy processes, and to identify potential opportunities to increase the adoption of recommended policies" with respect to a state government obesity prevention initiative. Other examples include the need for policies to address population growth, family size, and family planning to improve child health [28], housing, energy and wellbeing [27], and sugar-sweetened beverage tax to reduce sugar consumption and dental caries [33].

Informing practice was also a frequently identified intended use of CLDs (13/23) (Table 4). For example, Osman et al. [31] stated that their CLD could be used "to develop local action plans for implementation and consider strategies for mitigating possible future risks" and Parmar et al. [40] to develop "strategies to enhance capacities, services, and coordination to improve the health of refugees."

\section{For System Dynamics Modeling}

Five articles created CLDs for use in system dynamics modeling [26, 27, 38, 45] (Table 3). This was defined by Araz et al as "a computer-aided approach to model and facilitate analysis of complex system behaviors over time" [45]. They further described the steps in system dynamic modeling, and this was very much in line with other articles:

We first constructed a causal loop diagram (CLD) informed by the existing literature to present the causal relationships between variables in drugged driving behaviors and traffic safety policies. A stockflow diagram (SFD) was then used to convert these dynamic processes into quantitative expressions and a simulation tool [45].

Mirroring the above descriptions, Crielaard et al. [26] discussed the value of system dynamic modeling in terms of testing policy options from "studying 'what if scenarios using computational modelling approaches." It was notable that Urwannachotima et al. [33] and Swierad et al. [44] stated that the primary value of CLDs was in quantitative modelling.

\section{Measure and Evaluate Systems Change}

Table 4 identifies four articles that used CLDs to help measure and evaluate systems change [31, 39, 42, 48]. For example, Owen et al. [39] reported that "the methods provide a technique to retrospectively evaluate community interventions from a systems perspective and understand the way successful and unsuccessful 
interventions addressed complexity." They go further to explain that CLDs go beyond linear cause and effect logic models used in traditional evaluation and lessons regarding unintended consequences provide insights "to increase the chances of success for new prevention initiatives."

\section{Enhance Stakeholder and Community Participation} As discussed above, group model building (GMB) was a frequently reported process to create CLDs and inherent in these processes was the desire for stakeholder and/or community participation and shared understanding (Table 4). Gerritsen et al. [41] stated what many others did, that is, GMB helped people develop an understanding of the system under study and that "participants learn to see causal connections and how these connections result in patterns of behaviour evolving over time." They hypothesized that resulting plans for system change would be more successful with this fundamental level of participation and understanding. Another article highlighted that GMB brought diverse stakeholders "together to develop a system understanding of the problem, thus paving the way for further collaboration and community action" [44].

\section{Inform Future Research and Enhance Theoretical Perspectives}

The final two intended uses of CLDs were to inform future research and enhance theoretical perspectives (Table 4). These intended uses were not widely discussed and if at all, they were mostly short aspirational statements. However, one example where future research was explicitly discussed was provided by Swierad et al. [44]. Here they reported that "hypotheses" from a CLD of childhood obesity could be used in future research such as "impact of food eaten at school influencing norms and acceptability of western/packaged food, elasticity of grandparents' food norms, diversity of grandparents' ideal body image for children, or beliefs in health of traditional foods."

With respect to using CLDs to enhance theoretical perspectives, Clarke et al. [37] suggested that the CLD "enhanced previously published theoretical analyses of obesity prevention policy decision-making systems by making explicit how underlying feedback loops either spurred policy change or resistance." Another example is from Burrell et al. [36]. They reported that creating a CLD resulted in "a testable ecologically oriented theory of violence" and "the resulting model conveys new theoretical insights on how racial and economic features of urban settings interact with intrapsychic dimensions to create a self-perpetuating system of violence."

\section{DISCUSSION}

This section answers our second research question: What recommendations emerge regarding how to create and use CLDs in public health research? We offer nine learnings from the results above and interweave ideas from other research to support preliminary recommendations or possible directions to take forward in future research.

\section{Boundary Judgements}

We learned that some articles described in detail theoretical orientations with respect to complex systems thinking while others gave brief explanations. The most frequent concepts regarding complex systems were the inherent dynamic interactions among many entities, factors, variables that illustrate whole system structure and behavior. This is consistent with other public health literature on the topic [52-54]. The difference in descriptions was more a matter of comprehensiveness than definitions. For example, boundary judgement was not well articulated in the articles. According to Ulrich [55], drawing boundaries builds in selectivity and partiality and therefore transparency is important in study design. Therefore, we recommend that attention be given to defining boundaries to signal a specific endogenous perspective and a unique, snap-shot-in-time diagram of feedback loops of system behavior [56].

\section{From Theory to Leverage Points}

Some articles had strong theoretical coherence with respect to complex systems thinking that was demonstrated in discussions about the reasons for choosing, creating, and using CLDs. We learned that articles were most coherent when they first discussed feedback loops from a theoretical perspective and then carried this through to creating CLDs and to using them to identify leverage points for systems change (see for example 30). Overall, the descriptions of feedback in the articles were aligned with the idea that CLDs are "the applications of the loop concept underlying feedback and mutual causality" and that feedback loops are "powerful unifying notions that illuminate the structure of arguments, explanations, and causal views" [56]. Meadows [51] is well-known for explaining that disrupting or amplifying feedback loops can be effective leverage points in systems change. Therefore, we recommend that future research be designed with this theoretical coherence in mind.

\section{Theoretical Frameworks}

Lewin's famous statement that "there is nothing so practical as good theory" was salient for what we learned [57]. Few articles used theoretical frameworks in research design or discussed the need to advance theory (i.e., complexity, systems) in public health research. The articles that used frameworks appeared to be more robust especially with respect to embedding theoretical constructs in the resultant CLD (see for example 35). While we appreciate that theory is emerging, we recommend that this be given more emphasis to help continue to build a solid foundation for furthering the application of CLDs in public health research.

\section{Qualitative Data Analysis}

Knai et al. [30] pointed out that current public health research "concentrates mainly on a system's elements rather than the interconnections within it, and this is beginning to reveal its intrinsic limitations." Some articles described data analysis methods to identify variables and examine interconnections to 
draw CLDs, however, others lacked clear descriptions of the often highly iterative methods and therefore it was difficult to follow a data trail and assess the resultant CLD. We recommend that more clarity be provided as to how researchers innovate in qualitative data analysis to further develop the art and science of creating CLDs.

\section{Mixed Methods}

We found a range of research methods used to create CLDs. Ozawa et al. [58] state that mixed methods research is important

because it allows researchers to view problems from multiple perspectives, contextualize information, develop a more complete understanding of a problem, triangulate results, quantify hard-tomeasure constructs, provide illustrations of context for trends, examine processes/experiences along with outcomes and capture a macro picture of a system.

We hypothesize that mixed methods may produce more robust CLDs, however, this needs to be examined. We recommend that future research be undertaken to assess the strengths, limitations, and benefits of using mixed methods and determine what methods create greater confidence in the variables and feedback loops illustrated in CLDs.

\section{Participatory Action Research}

We found there was a wide range of who was involved in creating CLDs, from researchers only to multiple group model building sessions with stakeholders and community members. We see the latter methodology embedded in the traditions of action research [59] and/or community-based participatory research (CBPR) [60]. The CBPR approach involves "a commitment to conducting research that shares power with and engages community partners in the research process" and is intended "to increase knowledge and understanding of a given phenomena and integrate knowledge gained with interventions and policy and social change" [60]. There was little discussion of CBPR in the articles. We recommend that greater engagement with participatory action research literature be undertaken to embed the theory and philosophy of genuine participation and empowerment in research and action.

\section{Knowledge Translation}

There was limited discussion regarding how exactly CLDs were to be used to enhance evidence-informed policy and practice. Few articles explicitly discussed incorporating knowledge users or those able to use research results. As Sturmberg [61] relates, this requires users who are "deeply interested in understanding the highly interconnected and interdependent nature of the issues." This led us to think about the importance of knowledge translation (KT) and how to strengthen the use of CLDs. Haynes et al. [6] state that KT needs to be conceptualized as not "a discrete piece of work within wider efforts to strengthen public health, but as integral to and in continual dialogue with those efforts." We recommend that future public health research using CLDs should articulate KT plans that articulates knowledge user engagement in defining outcomes for strengthening public health policies and practices.

\section{Health Equity}

We conceptualize public health research to be guided by principles of social justice and human rights to address the goal of reducing health inequities through action on the determinants of health. Although many articles discussed determinants of health, the goal of reducing health inequities was largely absent. Baum et al. [62] discuss the concept of path dependency as "the tendency of institutions to retain policy directions and preferences rather than change or reform them." They further suggest that disrupting "path dependency that exacerbates health inequities" is critical and we see how CLDs could uncover path dependencies. We recommend that CLDs in public health research should include the examination of leverage points for pro-equity policy and practice.

\section{The Diagram}

Senge [63] states that "reality is made up of circles" but often arguments and explanations are linear, therefore, CLDs can provide "a language of interrelationships" to uncover deep patterns in systems. Studying the interrelationships and explanations of each CLD was outside the scope of this paper, however, we learned about some basic elements of reader friendly CLDs. We recommend that the following questions could be used assess CLDs: Are established conventions [56] used effectively for drawing the CLD (e.g., labeling, positive and negative arrows, reinforcing and balancing loops)? Does the diagram illuminate the most significant variables, feedback loops or leverage points? How well does the diagram function as an effective medium for presenting findings to knowledge users? How well does the CLD tell a story of what's going on in a system?

\section{Strengths and Limitations}

In terms of limitations, the 23 articles were not considered to be comprehensive. Since completing the study, we found that Mui and others [64] published an article on a community-based system dynamics approach and suggests solutions for improving healthy food access in a low-income urban environment. We also found Savona et al. [65] identified the views of adolescents regarding the causes of obesity and used CLDs. While this can be considered a limitation, we hope to see a continual building of knowledge and skill in using CLDs in public health research. A strength of this paper is that 23 recent articles were identified that used CLDs and the depth and breadth of discussion in the articles provided good representation. Having three authors conduct the literature review is also a strength because this afforded a high degree of confidence in reporting results and transparency in search strategy and data extraction, analysis and synthesis. Together the results and recommendations can contribute to informing global public health research by highlighting key considerations to help design research and address public health issues through complex systems thinking. 


\section{AUTHOR CONTRIBUTIONS}

LB designed the overall research aim and questions and $\mathrm{CN}$ provided input throughout the study. Study selection was conducted by LB. Appraisal and duplicate independent data extraction and validation was conducted by two authors (LB and $\mathrm{CH}$ ). $\mathrm{LB}$ and $\mathrm{CH}$ completed data analysis and all authors (LB, $\mathrm{CH}$, and $\mathrm{CN}$ ) provided input into writing the final manuscript.

\section{FUNDING}

The authors declare that this study received funding from Canadian Institutes for Health Research (LB/Postdoctoral fellowship) and the College of Medicine, University of

\section{REFERENCES}

1. Rutter H, Savona N, Glonti K, Bibby J, Cummins S, Finegood D, et al. The Need for a Complex Systems Model of Evidence for Public Health. The Lancet (2017) 390(10112):2602-4. doi:10.1016/s0140-6736(17)31267-9

2. Carey G, Malbon E, Carey N, Joyce A, Crammond B, Carey A. Systems Science and Systems Thinking for Public Health: a Systematic Review of the Field. BMJ Open (2015) 5(12):e009002. doi:10.1136/bmjopen-2015-009002

3. Chughtai S, Blanchet K. Systems Thinking in Public Health: a Bibliographic Contribution to a Meta-Narrative Review. Health Policy Plan (2017) 32(4): 585-94. doi:10.1093/heapol/czw159

4. Canadian Public Health Association. Public Health: A Conceptual Framework. Ottawa (2017).

5. Baugh Littlejohns L, Wilson A. Strengthening Complex Systems for Chronic Disease Prevention: a Systematic Review. BMC Public Health (2019) 19(1):729. doi:10.1186/s12889-019-7021-9

6. Haynes A, Rychetnik L, Finegood D, Irving M, Freebairn L, Hawe P. Applying Systems Thinking to Knowledge Mobilisation in Public Health. Health Res Pol Syst (2020) 18(1):134. doi:10.1186/s12961-020-00600-1

7. Egan M, McGill E, Penney T, Meier PS, Savona N, de Vocht F, et al. Complex Systems for Evaluation of Public Health Interventions: a Critical Review. The Lancet (2018) 392:S31. doi:10.1016/s0140-6736(18)32053-1

8. McGill E, Er V, Penney T, Egan M, White M, Meier P, et al. Evaluation of Public Health Interventions from a Complex Systems Perspective: A Research Methods Review. Soc Sci Med (2021) 272:113697. doi:10.1016/ j.socscimed.2021.113697

9. McGill E, Marks D, Er V, Penney T, Petticrew M, Egan M. Qualitative Process Evaluation from a Complex Systems Perspective: A Systematic Review and Framework for Public Health Evaluators. Plos Med (2020) 17(11):e1003368. doi:10.1371/journal.pmed.1003368

10. Rusoja E, Haynie D, Sievers J, Mustafee N, Nelson F, Reynolds M, et al. Thinking about Complexity in Health: A Systematic Review of the Key Systems Thinking and Complexity Ideas in Health. J Eval Clin Pract (2018) 24(3): 600-6. doi:10.1111/jep. 12856

11. Forrester JW. Learning through System Dynamics as Preparation for the 21st Century. Syst Dyn Rev (2016) 32(3-4):187-203. doi:10.1002/sdr.1571

12. Forrester J. Some Basic Concepts in System Dynamics. Boston: Sloan School of Management, Massachusetts Institute of Technology (2009).

13. Baugh Littlejohns L, Baum F, Lawless A, Freeman T. The Value of a Causal Loop Diagram in Exploring the Complex Interplay of Factors that Influence Health Promotion in a Multisectoral Health System in Australia. Health Res Pol Syst (2018) 16:126. doi:10.1186/s12961-018-0394-x

14. Paina L, Bennett S, Ssengooba F, Peters DH. Advancing the Application of Systems Thinking in Health: Exploring Dual Practice and its Management in Kampala, Uganda. Health Res Pol Sys (2014) 12(1):41. doi:10.1186/1478-4505$12-41$

15. Varghese J, Kutty VR, Paina L, Adam T. Advancing the Application of Systems Thinking in Health: Understanding the Growing Complexity Governing
Saskatchewan (CH/Dean's summer research project scholarship). Funding for the open access publication fee will be covered through the Canadian Institutes for Health Research award. The funders were not involved in the study design, collection, analysis, interpretation of data, the writing of this article or the decision to submit it for publication.

\section{CONFLICT OF INTEREST}

The authors declare that the research was conducted in the absence of any commercial or financial relationships that could be construed as a potential conflict of interest.

Immunization Services in Kerala, India. Health Res Pol Sys (2014) 12(1):47. doi:10.1186/1478-4505-12-47

16. Agyepong IA, Aryeetey GC, Nonvignon J, Asenso-Boadi F, Dzikunu H, Antwi E, et al. Advancing the Application of Systems Thinking in Health: Provider Payment and Service Supply Behaviour and Incentives in the Ghana National Health Insurance Scheme - a Systems Approach. Health Res Pol Sys (2014) 12 35. doi:10.1186/1478-4505-12-35

17. Biroscak BJ, Schneider T, Panzera AD, Bryant CA, McDermott RJ, Mayer AB, et al. Applying Systems Science to Evaluate a Community-Based Social Marketing Innovation. Soc Marketing Q (2014) 20(4):247-67. doi:10.1177/ 1524500414556649

18. Allender S, Owen B, Kuhlberg J, Lowe J, Nagorcka-Smith P, Whelan J, et al. .A Community Based Systems Diagram of Obesity Causes. PLoS ONE (2015) 10: e0129683. doi:10.1371/journal.pone.0129683

19. Homer J, Milstein B, Wile K, Pratibhu P, Farris R, Orenstein DR. Modeling the Local Dynamics of Cardiovascular Health: Risk Factors, Context, and Capacity. Prev Chronic Dis (2008) 5(2):A63

20. Brennan LK, Sabounchi NS, Kemner AL, Hovmand P. Systems Thinking in 49 Communities Related to Healthy Eating, Active Living, and Childhood Obesity. J Public Health Manag Pract (2015) 21:S55-69. doi:10.1097/ PHH.0000000000000248

21. Kopelman P, Jebb SA, Butland B. Foresight. Tackling Obesities: Future Choices Project Report. London: Government Office for Science (2007).

22. Munn Z, Peters MDJ, Stern C, Tufanaru C, McArthur A, Aromataris E. Systematic Review or Scoping Review? Guidance for Authors when Choosing between a Systematic or Scoping Review Approach. BMC Med Res Methodol (2018) 18(1):143. doi:10.1186/s12874-018-0611-x

23. Haddaway NR, Woodcock P, Macura B, Collins A. Making Literature Reviews More Reliable through Application of Lessons from Systematic Reviews. Conservation Biol (2015) 29(6):1596-605. doi:10.1111/cobi.12541

24. Byrne JA. Improving the Peer Review of Narrative Literature Reviews. Res Integr Peer Rev (2016) 1:12. doi:10.1186/s41073-016-0019-2

25. Hsiu-Fang H, Shannon SE. Three Approaches to Qualitative Content Analysis. Qual Health Res (2005) 15(9):1277. doi:10.1177/1049732305276687

26. Crielaard L, Dutta P, Quax R, Nicolaou M, Merabet N, Stronks K, et al. Social Norms and Obesity Prevalence: From Cohort to System Dynamics Models. Obes Rev (2020) 21(9):e13044. doi:10.1111/obr.13044

27. Eker NZ, Carnohan S, Davies M. Participatory System Dynamics Modelling for Housing, Energy and Wellbeing Interactions. Build Res Inf (2018) 46(7): 738-54. doi:10.1080/09613218.2017.1362919

28. Brereton CF, Jagals P. Applications of Systems Science to Understand and Manage Multiple Influences within Children's Environmental Health in Least Developed Countries: A Causal Loop Diagram Approach. Int J Environ Res Public Health (2021) 18(6). doi:10.3390/ijerph18063010

29. Klement RJ. Systems Thinking about SARS-CoV-2. Front Public Health (2020) 8(650):585229. doi:10.3389/fpubh.2020.585229

30. Knai C, Petticrew M, Mays N, Capewell S, Cassidy R, Cummins S, et al. Systems Thinking as a Framework for Analyzing Commercial Determinants of Health. Milbank Q (2018) 96(3):472-98. doi:10.1111/1468-0009.12339 
31. Osman M, Karat AS, Khan M, Meehan S-A, von Delft A, Brey Z, et al. Health System Determinants of Tuberculosis Mortality in South Africa: a Causal Loop Model. BMC Health Serv Res (2021) 21(1):388. doi:10.1186/s12913-02106398-0

32. Sahin O, Salim H, Suprun E, Richards R, MacAskill S, Heilgeist S, et al. Developing a Preliminary Causal Loop Diagram for Understanding the Wicked Complexity of the COVID-19 Pandemic. Systems (2020) 8(2):20. doi:10.3390/systems8020020

33. Urwannachotima N, Hanvoravongchai P, Ansah JP. Sugar-sweetened Beverage Tax and Potential Impact on Dental Caries in Thai Adults: An Evaluation Using the Group Model Building Approach. Syst Res (2019) 36(1): 87-99. doi:10.1002/sres.2546

34. Bradley DT, Mansouri MA, Kee F, Garcia LMT. A Systems Approach to Preventing and Responding to COVID-19. EClinicalMedicine (2020) 21: 100325. doi:10.1016/j.eclinm.2020.100325

35. Bensberg M, Joyce A, Wilson E. Building a Prevention System: Infrastructure to Strengthen Health Promotion Outcomes. Int J Environ Res Public Health (2021) 18(4):1618. doi:10.3390/ijerph18041618

36. Burrell M, White AM, Frerichs L, Funchess M, Cerulli C, DiGiovanni L, et al. Depicting "the System": How Structural Racism and Disenfranchisement in the United States Can Cause Dynamics in Community Violence Among Males in Urban Black Communities. Soc Sci Med (2021) 272:113469. doi:10.1016/ j.socscimed.2020.113469

37. Clarke B, Kwon J, Swinburn B, Sacks G. Understanding the Dynamics of Obesity Prevention Policy Decision-Making Using a Systems Perspective: A Case Study of Healthy Together Victoria. PLoS ONE (2021) 16(1):e0245535. doi:10.1371/journal.pone.0245535

38. Jalali MS, Rahmandad H, Bullock SL, Lee-Kwan SH, Gittelsohn J, Ammerman A. Dynamics of Intervention Adoption, Implementation, and Maintenance inside Organizations: the Case of an Obesity Prevention Initiative. Soc Sci Med (2019) 224:67-76. doi:10.1016/j.socscimed.2018.12.021

39. Owen B, Brown AD, Kuhlberg J, Millar L, Nichols M, Economos C, et al. Understanding a Successful Obesity Prevention Initiative in Children under 5 from a Systems Perspective. PLoS One (2018) 13(3):e0195141. doi:10.1371/ journal.pone.0195141

40. Parmar PK, Rawashdah F, Al-Ali N, Abu Al Rub R, Fawad M, Al Amire K, et al. Integrating Community Health Volunteers into Non-communicable Disease Management Among Syrian Refugees in Jordan: a Causal Loop Analysis. BMJ Open (2021) 11(4):e045455. doi:10.1136/bmjopen-2020-045455

41. Gerritsen S, Harré S, Rees D, Renker-Darby A, Bartos AE, Waterlander WE, et al. Community Group Model Building as a Method for Engaging Participants and Mobilising Action in Public Health. Int J Environ Res Public Health (2020) 17(10). doi:10.3390/ijerph17103457

42. Maitland N, Williams M, Jalaludin B, Allender S, Strugnell C, Brown A, et al. Campbelltown - Changing Our Future: Study Protocol for a Whole of System Approach to Childhood Obesity in South Western Sydney. BMC Public Health (2019) 19(1):1699. doi:10.1186/s12889-019-7936-1

43. Riley T, Hopkins L, Gomez M, Davidson S, Chamberlain D, Jacob J, et al. A Systems Thinking Methodology for Studying Prevention Efforts in Communities. Syst Pract Action Res (2020) 34 (5):555-73.

44. Swierad E, Huang TT, Ballard E, Flórez K, Li S. Developing a Socioculturally Nuanced Systems Model of Childhood Obesity in Manhattan's Chinese American Community via Group Model Building. J Obes (2020) 2020: 4819143. doi:10.1155/2020/4819143

45. Araz O, Wilson F, Stimpson J. Complex Systems Modeling for Evaluating Potential Impact of Traffic Safety Policies: a Case on Drug-Involved Fatal Crashes. Ann Operations Res (2020) 291(1-2):37-58. doi:10.1007/s10479-0182961-5

46. Hassmiller Lich K, Urban JB, Frerichs L, Dave G. Extending Systems Thinking in Planning and Evaluation Using Group Concept Mapping and System Dynamics to Tackle Complex Problems. Eval Program Plann (2017) 60: 254-64. doi:10.1016/j.evalprogplan.2016.10.008
47. Allender S, Brown AD, Bolton KA, Fraser P, Lowe J, Hovmand P. Translating Systems Thinking into Practice for Community Action on Childhood Obesity. Obes Rev (2019) 20:179-84. doi:10.1111/obr.12865

48. Brown A, Millar L, Hovmand PS, Kuhlberg J, Love P, Nagorcka-Smith P, et al. Learning to Track Systems Change Using Causal Loop Diagrams. Obes Res Clin Pract (2019) 13:73-4. doi:10.1016/j.orcp.2016.10.210

49. Kim H, Andersen DF. Building Confidence in Causal Maps Generated from Purposive Text Data: Mapping Transcripts of the Federal Reserve. Syst Dyn Rev (2012) 28(4):311-28. doi:10.1002/sdr.1480

50. Foster-Fishman PG, Nowell B, Yang H. Putting the System Back into Systems Change: a Framework for Understanding and Changing Organizational and Community Systems. Am J Community Psychol (2007) 39(3-4):197-215. doi:10.1007/s10464-007-9109-0

51. Meadows D. Leverage Points: Places to Intervene in a System. Norwich, Vermont: Donella Meadows Institute (1999).

52. Mabry PL, Marcus SE, Clark PI, Leischow SJ, Méndez D. Systems Science: a Revolution in Public Health Policy Research. Am J Public Health (2010) 100(7):1161-3. doi:10.2105/AJPH.2010.198176

53. Finegood D. The Complec Science of Obesity. In: J Cawley, editor. Handbook of the Social Science of Obesity. Oxford: Oxford University Press (2011).

54. Hawe P, Shiell A, Riley T. Theorising Interventions as Events in Systems. Am J Community Psychol (2009) 43(3-4):267-76. doi:10.1007/s10464-009-9229-9

55. Ulrich W. Beyond Methodology Choice: Critical Systems Thinking as Critically Systemic Discourse. J Oper Res Soc (2003) 54(4):325-42. doi:10.1057/palgrave.jors.2601518

56. Richardson G. Feedback Thought in Social Science and Systems Theory. Waltham, MA: Pegasus Communications, Inc. (1999).

57. Lewin K. Action Research and Minority Problems. J Soc Issues (1946) 2:34-46. doi:10.1111/j.1540-4560.1946.tb02295.x

58. Ozawa S, Pongpirul K. 10 Best Resources on ... Mixed Methods Research in Health Systems. Health Policy Plan (2013) 29(3):323-7. doi:10.1093/heapol/czt019

59. Bradbury H, Reason P, Publishing E, Ebsco V. The Sage Handbook of Action Research: Participative Inquiry and Practice. 2nd ed. London: SAGE (2012). p. ed2008.

60. B Israel, E Eng, A Schultz, E Parker, editors. Methods in Community-Based Participatory Research in Health. San Fransico, CA: Jossey-Bass (2005).

61. Sturmberg J. Without Systems and Complexity Thinking There Is No Progress - or Why Bureaucracy Needs to Become Curious. Int J Health Pol Manag (2021) 10(5):227-80. doi:10.34172/ijhpm.2020.45

62. Baum F, Townsend B, Fisher M. Creating Political Will for Action on Health Equity: Practical Lessons for Public Health Policy Actors. Int J Health Pol Manag (2020) x:1-14. doi:10.34172/ijhpm.2020.233

63. Senge P. The Fifth Discipline. New York: Doubleday (2006).

64. Mui Y, Ballard E, Lopatin E, Thornton RLJ, Pollack Porter KM, Gittelsohn J. A Community-Based System Dynamics Approach Suggests Solutions for Improving Healthy Food Access in a Low-Income Urban Environment. PLoS ONE (2019) 14:e0216985-13. doi:10.1371/journal.pone.0216985

65. Savona N, Macauley T, Aguiar A, Banik A, Boberska M, Brock J, et al. Identifying the Views of Adolescents in Five European Countries on the Drivers of Obesity Using Group Model Building. Eur J Public Health (2021) 31(2):391-6. doi:10.1093/eurpub/ckaa251

Copyright (C) 2021 Baugh Littlejohns, Hill and Neudorf. This is an open-access article distributed under the terms of the Creative Commons Attribution License (CC BY). The use, distribution or reproduction in other forums is permitted, provided the original author(s) and the copyright owner(s) are credited and that the original publication in this journal is cited, in accordance with accepted academic practice. No use, distribution or reproduction is permitted which does not comply with these terms.

PHR is edited by the Swiss School of Public Health (SSPH+) in a partnership with the Association of Schools of Public Health of the European Region (ASPHER)+ 